\title{
RISK FACTORS FOR SURGICAL SITE INFECTION IN COLON SURGERY IN OUR POPULATION.
}

\section{FACTORES DE RIESGO PARA INFECCIÓN DE SITIO QUIRÚRGICO EN CIRUGÍA COLÓNICA EN NUESTRA POBLACIÓN.}

\author{
Santiago Olguín Joseau ${ }^{1,4}$, Natalia Bollati ${ }^{1}$, Santiago Reimondez ${ }^{1}$, Franco Signorini ${ }^{1}$, Alejandro Mario Rossini ${ }^{2}$, Pablo \\ Sergio Maldonadoㄹ, Federico Moser ${ }^{1}$, Lucio Ricardo Obeide ${ }^{1}$, Álvaro Alcaraz', Juan Pablo Caeiro ${ }^{3}$.
}

1 Department of General Surgery. Hospital Privado Universitario de Córdoba.

2 Department of General Surgery. Hospital Raúl Ferreyra.

3 Department of Infectious Diseases. Hospital Privado Universitario de Córdoba.

4 Email de contacto: santiaolguin@gmail.com

\section{Abstract:}

Background: Surgical site infection (SSI) is the most common nosocomial infection in surgical patients with an incidence that varies between 5$30 \%$. Aim: Identify the risk factors for SSI in colonic surgery in our population. The secondary aims are to determine the incidence and type of $\mathrm{SSI}$, as well as the incidence of an anastomotic leakage ( $A L)$. Methods: Case-control study of patients undergoing colectomy between 20102014 at the Hospital Privado Univeristario de Córdoba and Hospital Raúl Ferreyra. Conventional and laparoscopic interventions, with a 30-day postoperative follow up, between 20-85 years and an ASA I-III were included. Patients undergoing emergency surgery and recto-anal resections were excluded. SSI was defined as an infection that occurred within 30 days after surgery. Results: We included 238 patients. SSI was diagnosed in $27.7 \%(n=66)$ of the patients of which $12.2 \%$ were superficial, $4.6 \%$ deep incisional and $10.9 \%$ organ/space. Multivariate analysis showed that SSI was independently associated with male sex (odds ratio [OR] 3.15; IC95\%:1.43-6.92; $\mathrm{p}=0.004$ ), having undergone previous chemotherapy (OR 6.72; IC95\%:1.4830.93; $\mathrm{p}=0.01$ ), need for conversion (OR 3.32; IC95\%:1.13-9.77; $p=0.02$ ), reintervention within the 30 postoperative days (OR 12.34; IC95\%:2.65-57.37, $\mathrm{p}=0.001$ ) and AL (OR 12.83; IC95\%:2.97- 55.5; $p=0.001)$. AL had an incidence of $9.6 \%$, of which $91 \%$ presented SSI and all were organ/space. Conclusion: We found that male sex, having undergone previous chemotherapy, conversion, reintervention within 30 postoperative days and $A L$ are risk factors for SSI in our population. These results should be considered in implementing preventive measures for SSI.

Keywords: surgical wound infection; risk factors; colectomy.

\section{Resumen:}

Introducción: La infección de sitio quirúrgico (ISQ) es la infección intrahospitalaria más frecuente en los pacientes quirúrgicos con una incidencia entre 5-30\%. Objetivos: Identificar los factores de riesgo para ISQ en cirugía colónica en nuestra población. Los objetivos secundarios son determinar la incidencia y tipo de ISQ, así como la incidencia de dehiscencia de anastomosis (DA). Materiales y métodos: Estudio de casos-controles de pacientes intervenidos de colectomía entre 2010-2014 en el Hospital Privado Universitario de Córdoba y Hospital Raúl Ferreyra. Se incluyeron las intervenciones convencionales y laparoscópicas, con seguimiento de 30 días, pacientes entre 20 y 85 años y con ASA I-III. Se excluyeron las cirugías de urgencia y las resecciones recto-anales. Se definió ISQ a aquella que ocurre dentro de 30 días. Resultados: Se incluyeron 238 pacientes. Se diagnosticó ISQ en $27,7 \% \quad(n=66)$ de los pacientes de los cuales $12,2 \%$ fue superficial, $4,6 \%$ profunda y $10,9 \%$ de órgano/espacio. El análisis multivariado demostró que la ISQ se asocia con sexo masculino (odds ratio [OR] 3,15; IC95\%:1,43-6,92; $\quad \mathrm{p}=0,004), \quad$ quimioterapia neoadyuvante (OR 6,72; IC95\%:1,48-30,93; $\mathrm{p}=0,01$ ), conversión (OR 3,32; IC95\%:1,13-9,77; $\mathrm{p}=0,02)$, reintervención dentro de 30 días postquirúrgicos (OR 12,34; IC95\%:2,65-57,37, $\mathrm{p}=0,001)$ y $\mathrm{DA}$ (OR 12,83; IC95\%:2,97- 55,5; $p=0,001)$. La DA presenta una incidencia del $9,6 \%$, de los cuales el $91 \%$ presentó ISQ y todas fueron de órgano/espacio. Conclusión: Sexo masculino, quimioterapia neoadyuvante, conversión, reintervención dentro de 30 días postquirúrgicos y DA son factores de riesgo para ISQ en nuestra población. Estos resultados deben ser considerados para implementar medidas preventivas para ISQ.

Palabras clave: infección de la herida quirúrgica; factores de riesgo; colectomía. 


\section{Introduction}

Surgical site infection (SSI) is the most common nosocomial infection in surgical patients with an incidence that varies between 5 and $30 \% \%^{1,2}$. It is associated with prolonged postoperative hospital length of stay and an increase in morbidity and costs ${ }^{3}$.

SSI is defined as an infection that occurs within the 30 postoperative days ${ }^{1}$. The Center for Disease Control and Prevention and the American College of Surgeon National Surgical Quality Improvement Program (ACS-NSQIP) divides SSI into three distinct types based on the anatomic level of infection in superficial (skin), deep incisional (deep soft tissue and/or muscle) and organ/space (within the abdomen) ${ }^{4}$.

Anastomotic leak $(A L)$ after colonic surgery has an incidence ranging from 1.8 to $15.9 \%$. As happens with $\mathrm{SSI}, \mathrm{AL}$ is associated with prolonged postoperative hospital length of stay and an increase in morbidity and $\operatorname{costs}^{4,5}$.

Although multiple risk factors have been published for $\mathrm{SSI}^{3-12}$, there is no consensus about their impact on our population.

The principal aim of our study is to identify risk factors for SSI in colonic surgery in our population. The secondary aims are to determine the incidence and type of SSI, as well as de incidence of $\mathrm{AL}$.

\section{Methods}

We performed a retrospective case-control study in which the medical history of patients undergoing scheduled colectomy was reviewed between February 2010 and December 2014 at Hospital Privado Univeristario de Córdoba and Hospital Raúl Ferreyra.

Conventional and laparoscopic interventions, with a 30-day postoperative follow up, aged between 20-85 years and an ASA I-III were included. Patients undergoing emergency surgery, younger than 20 and older than 85 years, and recto-anal resections were excluded.

Demographic data, colectomy indication, type of surgery, surgical time, need for conversion, mechanical bowel preparation, type of anastomosis, hypotension and transfusions were analyzed. Post-surgical variables included SSI, AL, urinary infection, tumor stage, reintervention, transfusion, death and hospital length of stay.

SSI was considered as an infection that occurred within 30 days after surgery and was classified according to ACS-NSQIP 4 .

$\mathrm{AL}$ was considered organ/space SSI when it compromised the patient clinical condition and required treatment change. We classified $\mathrm{AL}$ according to Rahbari ${ }^{13}$ into three grades: grade $\mathrm{A}$ does not require changes in the patient treatment; grade $B$, requires changes in treatment, but without surgical reintervention; and grade $\mathrm{C}$, requires surgical reintervention.

The principles of Helsinki declaration were respected.

Qualitative variables were analyzed with chi-square test while the quantitative variables were analyzed with the $\mathrm{T}$ test. We identified the variables independently associated with SSI from the multivariate analysis. For the statistical analysis, the IBM SPSS Statistics 21 program was used.

\section{Results}

We included 238 patients who met the inclusion criteria between February 2010 and December 2014. In the same period 165 patients were excluded. The mean age was of 65 years and $54.6 \%$ were men.

SSI was diagnosed in $27.7 \%(n=66)$ of which $12.2 \%(n=29)$ were superficial, $4.6 \%(n=11)$ deep incisional and $10.9 \%(n=26)$ organ/space. The mean time of diagnosis was 6.5 days. The mean hospitalization rate was 14.5 days in patients with SSI compared to 7.7 days in those with normal evolution $(p=0.001)$. There were 12 deaths of which $6(2.5 \%)$ were in patients with SSI ( $p=0.7)$. Tables 1,2 and 3 summarize the demographic, surgical, and perioperative variables, respectively. In addition, it presents the incidence of SSI according to each variable. 
Table 1: Patients characteristics

\begin{tabular}{lccc}
\hline \multicolumn{1}{c}{ Variables } & SSI + & SSI - & p \\
\hline Age (mean and SD) & $64,6(12,4)$ & $65,1(12,4)$ & 0,68 \\
\hline Sex (n \& \%) & & \\
\hline Male & $43(18,1 \%)$ & $87(36,6 \%)$ & 0,04 \\
Female & $23(9,7 \%)$ & $85(35,7 \%)$ & 0,04 \\
\hline BMI (mean and SD) & $27,6(5,1)$ & $26,7(4,7)$ & 0,26 \\
\hline ASA (n \&\%) & & \\
\hline I & $1(0,4 \%)$ & $4(1,7 \%)$ & 1 \\
II & $45(19,1 \%)$ & $110(46,6 \%)$ & 0,61 \\
III & $20(8,5 \%)$ & $56(23,7 \%)$ & 0,69 \\
\hline Comorbidities (n \& \%) & & \\
\hline Arterial hypertension & $40(16,8 \%)$ & $94(39,5 \%)$ & 0,4 \\
Diabetes & $10(4,2 \%)$ & $16(6,7 \%)$ & 0,19 \\
Ischemic heart disease & $6(2,5 \%)$ & $15(6,3 \%)$ & 0,92 \\
Heart failure & $2(0,8 \%)$ & $4(1,7 \%)$ & 0,67 \\
Asthma & $3(1,3 \%)$ & $10(4,2 \%)$ & 1 \\
COPD & $1(0,4 \%)$ & $8(3,4 \%)$ & 0,45 \\
Smoking & $31(13 \%)$ & $78(32,8 \%)$ & 0,82 \\
Previous stoma & $2(0,8 \%)$ & $3(1,3 \%)$ & 0,61 \\
Previous chemotherapy & $5(2,1 \%)$ & $4(1,7 \%)$ & 0,06 \\
Previous laparotomies & $30(12,6 \%)$ & $59(24,8 \%)$ & 0,11 \\
Previous hemoglobin (Mean and DS) & $13,5(20,3)$ & $11,3(1,97)$ & 0,4 \\
Previous blood glucose (Media y DS) & $125(46,7)$ & $124(38,4)$ & 0,95 \\
Weight loss > 10\% in six months & $13(5,5 \%)$ & $28(11,8 \%)$ & 0,53 \\
\hline \multicolumn{4}{c}{ SD (Standard deviation), BMI (Body mass index), COPD (Chronic obstructive pulmonary disease). } \\
\end{tabular}

Table 2: Surgery variables and type of SSI.

\begin{tabular}{lccccc}
\hline \multicolumn{1}{c}{ Variables } & SSI & Superficial & Deep incisional & Organ/space & p \\
\hline Technique & & & & & \\
\hline Laparoscopic & $13,90 \%$ & $6,30 \%$ & $0,80 \%$ & $6,70 \%$ & 0,16 \\
Conventional & $13,90 \%$ & $5,90 \%$ & $3,80 \%$ & $4,20 \%$ & 0,16 \\
Conversion & $4,60 \%$ & $2,50 \%$ & $0,40 \%$ & $1,70 \%$ & 0,01 \\
\hline Colectomy & & & & & \\
\hline Right & $13,40 \%$ & $7,10 \%$ & $1,70 \%$ & $4,60 \%$ & 0,15 \\
Left & $9,20 \%$ & $2,90 \%$ & $2,10 \%$ & $4,20 \%$ & 0,33 \\
Sigmoid & $2,50 \%$ & $1,70 \%$ & $0,40 \%$ & $0,40 \%$ & 0,08 \\
Segmentary & $2,50 \%$ & $0,40 \%$ & $0,40 \%$ & $1,70 \%$ & 0,98 \\
\hline
\end{tabular}

Table 3: Surgery and postoperative variables.

\begin{tabular}{lccc}
\hline \multicolumn{1}{c}{ Variables } & SSI + & SSI - & p \\
\hline Surgical time (Mean y SD) & $179(58,5)$ & $166,5(61,1)$ & 0,15 \\
Additional procedure (n \& \%) & $22(9,2 \%)$ & $49(20,6 \%)$ & 0,4 \\
Hypotension (n \& \%) & $20(8,4 \%)$ & $24(10,1 \%)$ & 0,004 \\
Intraoperative transfusion (n \& \%) & $23(9,7 \%)$ & $41(17,2 \%)$ & 0,08 \\
Blood glucose (Mean y SD) & $155(48)$ & $143(41)$ & 0,16 \\
Reintervention (n \& \%) & $18(7,6 \%)$ & $3(1,3 \%)$ & 0,001 \\
Postoperative transfusion (n \& \%) & $24(10,1 \%)$ & $23(9,7 \%)$ & 0,001 \\
\hline Stage (n \& \%) & & \\
\hline I & $10(4,2 \%)$ & $18(7,6 \%)$ & 0,31 \\
IIA & $13(5,5 \%)$ & $22(9,2 \%)$ & 0,17 \\
IIB & $1(0,4 \%)$ & $1(0,4 \%)$ & 0,47 \\
IIC & $1(0,4 \%)$ & $0(0 \%)$ & 0,27 \\
IIIA & $2(0,8 \%)$ & $7(2,9 \%)$ & 1 \\
IIIB & $9(3,8 \%)$ & $35(14,7 \%)$ & 0,23 \\
IIIC & $2(0,8 \%)$ & $5(2,1 \%)$ & 1 \\
IV & $10(4,2 \%)$ & $19(8 \%)$ & 0,38 \\
\hline
\end{tabular}


The most frequent indication for surgery was colon cancer (69\%). When compared to the rest of indications for surgery, those patients with cancer where more likely to have $S S I(p=0.05)$ but it was not found as a risk factor.

Mechanical bowel preparation was performed in 98\%. Polyethylene glycol was the most used (95\%) and it was associated with SSI $(25.3 \%$; $p=0.04)$ but It was not a risk factor for the multivariate analysis.

No differences were found between the types of anastomosis. Manual anastomosis presented $29.3 \%$ of SSI while the mechanical anastomosis $25.8 \%(p=0.7 ; p=0.45)$. We also considered side to side, end to end and end to side anastomosis and no differences were found for SSI. Table 2 includes these results.

The multivariate analysis showed that SSI was independently associated with male sex (odds ratio [OR] 3.15; IC95\%:1.43-6.92; $p=0.004$ ), having undergone previous chemotherapy (OR 6.72; IC95\%:1.48-30.93; $\mathrm{p}=0.01$ ), need for conversion (OR 3.32; IC95\%:1.13-9.77; $\mathrm{p}=: 0.02$ ), reintervention within 30 postoperative days (OR 12.34; IC95\%:2.65-57.37, $\mathrm{p}=0.001$ ) and AL (OR 12.83; IC95\%:2.97-55.5; $\mathrm{p:} \mathrm{0.001).}$

AL had an incidence of $9.6 \%(n=23)$ of which $91 \%(n=21)$ presented SSI and all were organ/space. Surgical reintervention was required for septic shock in 13 patients, intravenous antibiotics and total parenteral nutrition in 8 , and not making changes in treatment in 2.

\section{Discussion}

$\mathrm{SSI}$ is a frequent problem in the postoperative period of colonic surgery. There have been multiple risk factors related to SSI published. The incidence for SSI was $27.7 \%$ in this study, similar to other series ${ }^{3-12}$. Male sex has previously been described as a risk factor for $\mathrm{SSI}^{9,5,12,14}$. Among them Tserenpuntsag ${ }^{9}$ and Gomila $^{14}$ identified male sex as a risk factor for SSI in a case control study and in a cohort study respectively ( $n=2656$, OR:1.34, IC95\%:1.1-1.6; $n=3701$, OR:1.57, IC95\%:1.14-2.15, p=0.004 respectively).

Regarding previous chemotherapy in colonic surgery in our study, 6 patients undergone chemotherapy because of colon cancer with liver metastases that underwent neoadjuvant therapy, 2 patients with previous colectomy and adjuvant therapy with recurrence at anastomosis, and 1 with seminoma with peritoneal metastases that required adjuvant therapy. Degrate ${ }^{15}$ performed a study that included 277 patients and divided them according to the resected site (rectum, right and left colon) where previous chemotherapy was identified as a risk factor for $S S I(p=0.02)$ although this was only found in rectal surgery. Lawson ${ }^{4}$ conducted a cohort study involving 27011 patients and Drosdeck ${ }^{16}$ conducted a study that analyzed risk factors for SSI in colorectal laparoscopic surgery, where they found no statistically significant association regarding previous chemotherapy ( $p=0.18 ; p=0.99$ respectively). In previous studies we found data that associates previous chemotherapy as a risk factor for $A L$ in colonic surgery, among them are Mungo $^{17}$ and Midura ${ }^{5}$ (OR:1.97, IC95\%: 1.6-2.4, p=0.001; OR:1.71, IC95\%: 1.1-2.5, $\mathrm{p}=0.007$ respectively). Mungo ${ }^{17}$ associated the need for conversion in colonic surgery to an increased risk of $\mathrm{AL}$, mortality and hospital readmission $(p=0.001)$. The relationship between the need for conversion and SSI could be explained by the increase of surgical time, as has been demonstrated in previous series. Lawson ${ }^{4}$ described an upward relationship between surgical time and SSI of any type. The risk of deep SSI and organ/space increased from $4.4 \%$ in the shortest surgical time to $9.5 \%$ in the largest. Likewise, other authors $^{18-20,12}$ have identified the increase of surgical time above 3 hours as a risk factor for SSI in colonic surgery with statistically significant results.

In our population $A L$ had an incidence of $9.7 \%$ of which $91 \%(n=21)$ presented $S S I$ and all were organ/space. According to Rahbari ${ }^{13}$, there were 2 grades $A$ that required no change in treatment, 8 grades $B$ requiring intravenous antibiotics and total parenteral nutrition; and 13 grades $C$ who required surgical reintervention due to septic shock. AL causes leakage of intestinal contents into the abdominal cavity, which may spontaneously drain through drainage or may cause SSI of organ/space and increase the risk of septic shock and the need of reintervention. Lawson ${ }^{4}$ identified AL as a risk factor for SSI (OR: 2.06, $\mathrm{p}=0.001$ ).

In our population $8.8 \%(n=21)$ required surgical reintervention within the first 30 postoperative days. Of these, $61.9 \%$ were due to septic shock caused by SSI due to anastomosis leak $(p=0.001)$. This could explain why the need of reintervention was identified as a risk factor for SSI. The rest of the reinterventions 
were due to hemorrhage $(n=4)$, ostomal invagination $(n=1)$, evisceration $(n=1)$, and abscesses without $A L$ $(\mathrm{n}=2)$.

Cannon $^{21}$ in a cohort study that included 9940 patients, and Degrate ${ }^{15}$ in their previously mentioned study, showed that right colon resection has less SSI than left colon $(12.8 \%$ vs. $19.6 \%, p=0.0001 ; 8 \%$ vs $18.4 \%$, $\mathrm{p}=0.02$ respectively). This is not the case in our population where right colectomy has more SSI than left (32.7\% vs $24.2 \%, \mathrm{p}=0.06)$.

This study has some limitations which includes a retrospective non-randomized study with a small number of patients. As a retrospective study, the data collection on the identification of SSI and postoperative follow-up is subject to the criteria of the attending physician. However, we believe this study demonstrates the risk factors for SSI in our population and allows us to take the necessary measures to prevent it.

In conclusion, we found that male sex, having undergone previous chemotherapy, the need to convert from laparoscopic to conventional technique, reintervention within the first 30 postoperative days and $A L$ are risk factors for SSI in our population. These results should be considered in implementing preventive measures for SSI and in planning prospective studies to confirm them.

\section{Bibliografía}

1- Sadahiro S, Suzuki T, Tanaka A, Okada K, Kamata H, Ozaki T, et al. Comparison between oral antibiotics and probiotics as bowel preparation for elective colon cancer surgery to prevent infection: Prospective randomized trial. Surgery. 2014; 155(3):493-503.

2- Fry DE. The prevention of surgical site infection in elective colon surgery. Scientifica. Vol 2013; Article ID 896297, 19 pages, 2013.

3- Segal CG, Waller DK, Tilley B, Piller $L$ and Bilimoria $K$. An evaluation on differences in risk factors for individual types of surgical site infections after colon surgery. Surgery. 2014; 156(5):1253-60.

4- Lawson EH, Hall BL and Ko CY. Risk factors for superficial vs deep/organ-space surgical site infections: Implications for quality improvement initiatives. JAMA Surg. 2013; 148(9):849-58.

5- Midura EF, Hanseman D, Davis BR, Atkinson SJ, Abbott DE, Shah SA, et al. Risk factors and consequences of anastomotic leak after colectomy: a national analysis. Dis Colon Rectum. 2015; 58(3):333-8.

6- Rovera F, Dionigi G, Boni L, Piscopo C, Masciocchi P, Alberio MG, et al. Infectious complications in colorectal surgery. Surg Oncol. 2007; 16:121-124.

7- Ishikawa K, Kusumi T, Hosokawa M, Nishida Y, Sumikawa S and Furukawa H. Incisional surgical site infection after elective open surgery for colorectal cancer. Int J Surg Oncol. 2014; 2014:419712.

8- Hedrick TL, Heckman JA, Smith RL, Sawyer RG, Friel CM and Foley EF. Efficacy of protocol implementation on incidence of wound infection in colorectal operations. J Am Coll Surg. 2007; 205(3):432-438.

9- Tserenpuntsag B, Haley V, Van Antwerpen C, Doughty D, Gase KA, Hazamy PA, et al. Surgical site infection risk factors identified for patients undergoing colon procedures, New York State 2009-2010. Infect Control Hosp Epidemiol. 2014; 35(8):1006-12.

10- Nakamura T, Mitomi H, Ihara A, Onozato W, Sato T, Ozawa H, et al. Risk factors for wound infection after colorectal cancer. World J Surg. 2008; 32(6):1138-41.

11- Acín-Gándara D, Rodríguez-Caravaca G, Durán-Poveda M, Pereira-Pérez F, Carrión-Álvarez L, Fernández-Cebrián JM, et al. Incidence of surgical site infection in colon surgery: comparison with regional, national Spanish and United States standards. Surg Infect. 2013; 14(4):339-344.

12- Eagye KJ and Nicolau DP. Deep and organ/space infections in patients undergoing elective colorectal surgery: Incidence and impact on hospital length of stay and costs. Am J Surg. 2009; 198(3):359-367.

13- Rahbari NN, Weitz J, Hohenberger W, Heald RJ, Moran B, Ulrich A, et al. Definition and grading of anastomotic leakage following anterior resection of the rectum: A proposal by de international study group of Rectal Cancer. Surgery. 2010; 147(3):339-351.

14- Gomila A, Carratala J, Camprubí D, Shaw E, Badia JM, Cruz A, et al. Risk factors and outcomes of organ-space surgical site infections after elective colon and rectal surgery. Antimicrob Resist Infect Control. 2017; 6:40.

15- Degrate L, Garancini M, Misani M, Poli S, Nobili C, Romano F, et al. Right colon, left colon, and rectal surgeries are not similar for surgical site infection development. Analysis of 277 elective and urgent colorectal resections. Int $J$ Colorectal Dis. 2010; 26(1):61-69.

16- Drosdeck J, Harzman A, Suzo A, Arnold M, Abdel-Rasoul M and Husain S. Multivariate analysis of risk factors for surgical site infection after laparoscopic colorectal surgery. Surg Endosc. 2013; 27(12):4574-4580.

17- Mungo B, Papageorge CM, Stem M, Molena $D$ and Lidor AO. The impact of operative approach on postoperative complications following colectomy for colon cancer. World J Surg. 2017; 41(8):2143-2152.

18- Konishi T, Watanabe T, Kishimoto $J$ and Nagawa $H$. Elective colon and rectal surgery differ in risk factors for wound infection. Results of prospective surveillance. Ann Surg. 2006; 244(5):758-763.

19- Hennessey DB, Burke JP, Ni-Dhonochu T, Shields C, Winter DC and Mealy K. Risk factors for surgical site infection following colorectal resection: a multi-institutional study. Int J Colorectal Dis. 2016; 31(2):267-71.

20- Murray AC, Pasam R, Estrada D and Kiran RP. Risk of surgical site infection varies based on location of disease and segment of colorectal resection for cancer. Dis Colon Rectum. 2016; 59(6):493-500.

21- Cannon JA, Altom LK, Deierhoi RJ, Morris M, Richman JS, Vick CC, et al. Preoperative oral antibiotics reduce surgical site infection following elective colorectal resections. Dis Colon Rectum. 2012; 55(11):1160-1166. 